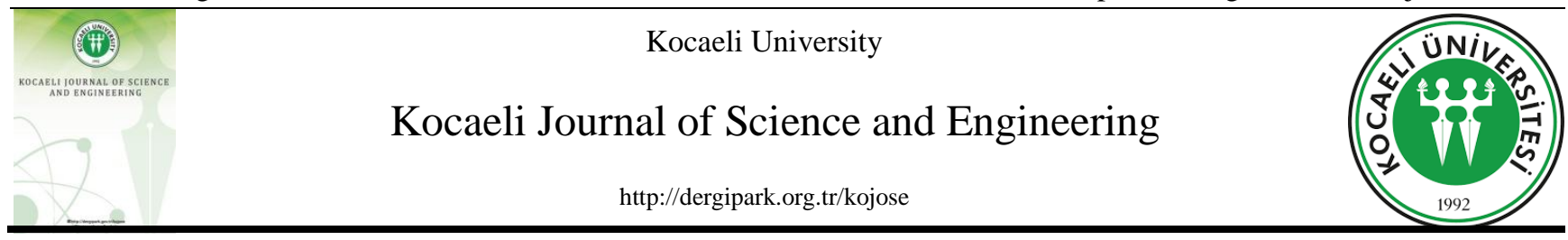

\title{
Experimental and Numerical Investigation of Crack Propagation in Spherical Porous Cylindrical Specimen under Mixed Mode Loading
}

\author{
Sedat İRIÇ ${ }^{1, *}$ iD \\ ${ }^{I}$ Department of Mechanical Engineering, Sakarya University, Sakarya, 54187, Turkey, ORCID: 0000-0001-8477-7906
}

\begin{tabular}{|c|c|}
\hline \multicolumn{2}{|c|}{ Article Info } \\
\hline \multicolumn{2}{|c|}{ Research paper } \\
\hline Received & : October 02,2020 \\
\hline Accepted & : October 22, 2020 \\
\hline \multicolumn{2}{|c|}{ Keywords } \\
\hline \multicolumn{2}{|c|}{$\begin{array}{l}\text { Crack Propagation } \\
\text { Finite Element Simulation } \\
\text { Fracture Mechanics } \\
\text { Fracture Toughness } \\
\text { Stress Intensity Factor }\end{array}$} \\
\hline
\end{tabular}

\begin{abstract}
In this study, mixed mode I/III fatigue crack propagation is examined experimentally and numerically by using spherical porous cylindrical specimen. The crack propagation path, profiles of crack front, the differences of stress intensity factors (SIF) and equivalent SIF were computed by ANSYS, FCPAS and SOLIDWORKS softwares and compared with experimental data. Modeling, meshing and problem solving were performed using ANSYS, and the resulting SIF and equivalent SIF along the crack front were calculated using FCPAS. Two digital cameras were used to observing the crack growth path and fractured surfaces on specimen under mixed mode loading, and the obtained images were converted into 3D CAD data by using SOLIDWORKS software. It was found that good agreements were achieved between the results of the experiment and simulation considering both evolving the crack propagation paths and crack front.
\end{abstract}

\section{Introduction}

The applications of fracture mechanics have mainly focused on the prediction of the fatigue crack propagation and life of defective structures under mode I loading condition. But in industry, many service failures occur due to the crack is not perpendicular to the loading direction (mode I ) or the structure is subjected to multiaxial (mixed mode) loadings. Under such mixed mode (mode I/III) loading conditions, out of plane (Mode III) loading can accelerate crack growth, and the crack may deviate from the original crack path. Thus, thorough understanding and knowledge of mechanisms driving mixed mode fracture and crack growth conditions are necessary for accurate assessment of such conditions computationally and experimentally. Linear elastic fracture mechanics (LEFM) approach has been widely used in analyzing the fatigue crack behavior where elastic stress-strain field in the vicinity of crack front is usually evaluated by calculating the SIF [1]. To investigate the SIF under mixed mode I/III loading conditions, some studies were performed experimentally and numerically. Yang et al. studied

*Corresponding Author: siric@sakarya.edu.tr prediction of shape change for fatigue crack and validated by comparing the solution with other simulation solutions and experimental data [2]. Lin et al. examined the fatigue growth of surface, internal and multiple cracks in both notched and unnotched round bars subjected to remote tension or bending loads [3].Van et al. investigated the problem of crack propagation behaviour under tensile or bending fatigue loads. Comparisons were made with analytical, experimental and numerical results available in the literature [4]. Chaves et al. tested specimens with circular holes of various diameters under tension, torsion and in-phase biaxial loading [5]. Fatemi et al. investigated fatigue crack growth behaviour of tubular aluminium specimens with a circular hole under axial and torsional loadings [6]. Liu proposed various criteria for the calculation of effective mixed-mode SIF [7]. Schollmann et al., Sih et al. and Pook have developed threedimensional (3D) criteria for the prediction of crack propagation, crack front profile and equivalent SIF [8-10]. Demir et al. have proposed a mixed mode I/II/III fracture criterion using both numerical and experimental analyses results [11]. Erdogan et al. have proposed the maximum tangential stress criterion [12]. Kurt et al. have made several 3D mixed mode fatigue crack propagation simulation using FCPAS software [13]. In this paper, 
numerical and experimental analyses were performed using spherical porous cylindrical specimen made of $\mathrm{Al}$ 7075-T651 to compare crack paths under tensile and torsion loadings.

\section{Experimental Method}

Test specimen used in this investigation was prepared from aluminum alloy 7075-T651 with $30 \mathrm{~mm}$ diameter. The mechanical properties of the alloy and the constants of the Paris equation in Eq. (1) for this material are listed in Table 1. In Eq. (1), E is the Young's modulus, $\sigma_{\mathrm{y}}$ is the yield tensile strength, $\mathrm{C}$ and $\mathrm{m}$ are the Paris constants. The Paris constants and fracture toughness $\left(\mathrm{K}_{\mathrm{IC}}\right)$ of the materials were determined using standard notched and precracked specimens [14-15].

Table 1. Main mechanical properties of Aluminum alloy 7075-651 [11].

\begin{tabular}{|l|l|l|l|l|l|}
\hline $\begin{array}{l}\mathrm{E} \\
(\mathrm{GPa})\end{array}$ & $\begin{array}{l}\sigma_{\mathrm{y}} \\
(\mathrm{MPa})\end{array}$ & $v$ & $\begin{array}{l}\mathrm{K}_{\mathrm{IC}} \\
(\mathrm{MPa} \sqrt{\mathrm{m}})\end{array}$ & $\begin{array}{l}\mathrm{C} \\
\left(\mathrm{x} 10^{-7}\right)\end{array}$ & $\mathrm{m}$ \\
\hline 70 & 500 & 0.33 & 29.6 & 2.28 & 3.11 \\
\hline
\end{tabular}

$\frac{d a}{d N}=C \Delta K_{e q}^{m}$

The specimen geometry and test section dimensions are shown in Figure 1. A ball nose end mill cutter was used to prepare a spherical porous on one side of the specimen.

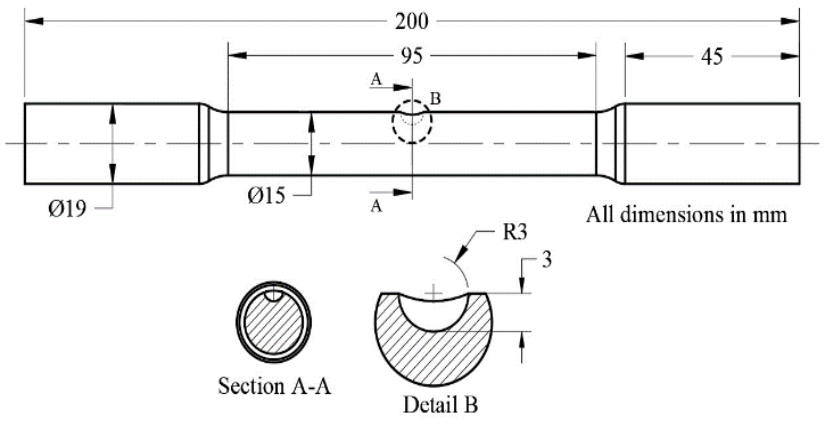

Figure 1. Details of the specimen geometry.

The axial/torsional test system (MTS 809) was used for mixed mode fatigue crack propagation testing of the specimen shown in Figure 2(a). The system was equipped with axial-torsional load cell with an axial capacity of 100 $\mathrm{kN}$ and torsional capacity of $1100 \mathrm{Nm}$. Before preparing the test setup, a finite element analysis (FEA) was performed to find maximum stress zone. Two independent 800x usb digital microscope cameras were used for the monitoring of the crack shown in Figure 2(c). Red color shows the maximum stress zone where are possible cracks initiation locations. The cameras were positioned to observe these area. This system has enabled simultaneous observation of two sides of the specimen during the fatigue test.
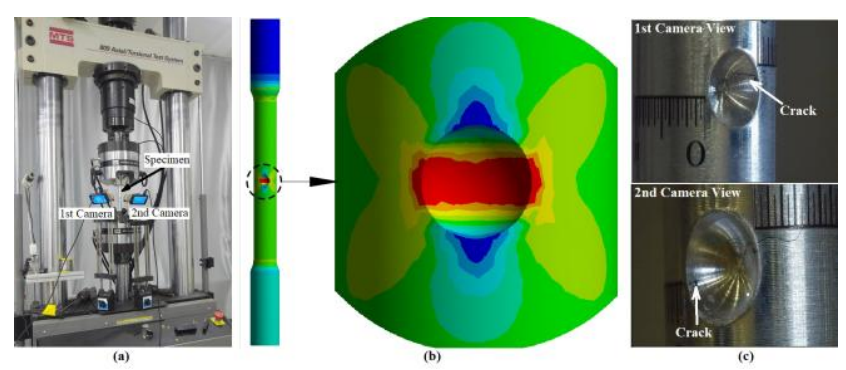

Figure 2. (a) Test setup (b) Maximum stress zone (c) Views of cameras.

The fatigue pre-crack was done at a maximum tensile load of $50 \mathrm{kN}$ and the stress ratio $\mathrm{R}=0.1$. The test was stopped, when the surface crack length (a) observed with cameras was approximately equal to $1 \mathrm{~mm}$ (Figure 3(c)). Digital image observations of the specimen fractured surfaces were carried out in order to find the geometry of the pre-crack front shown in Figure 2(a-b). Obtained images were converted to 2D curve using curve fitting tool that is inside the SOLIDWORKS software. The blue dashed curve shown in Figure 2(c) was used to define the front of the crack for the fatigue crack propagation simulation under mixed-mode loading.
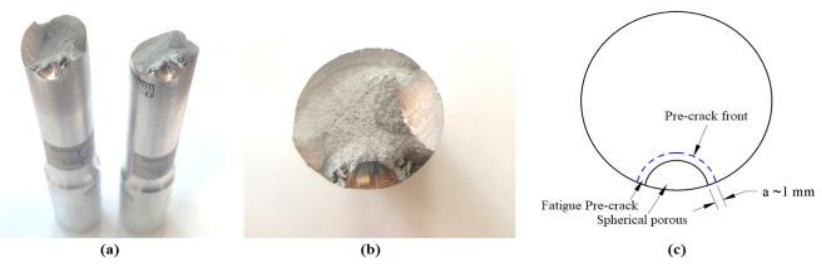

Figure 3. (a) Perspective view (b) Top view (c) Schematic representation of the pre-cracked section.

\section{Numerical Modeling and Analysis}

ANSYS, SOLIDWORKS and FCPAS software were used for modeling and analyzing the mixed mode fatigue crack propagation. The process steps of the analysis procedure are shown in Figure 4.

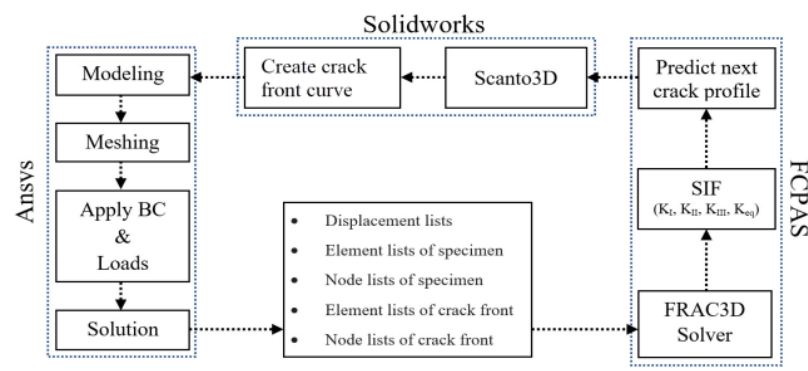

Figure 4. A detailed scheme of a fatigue crack propagation analysis. 
The finite element model of the specimen was modeled as shown in Figure 1, and applied $40 \mathrm{kN}$ tension and $150 \mathrm{Nm}$ torsion loadings similar to the test conditions. Hexahedral enriched elements showed in red colour and transition elements showed in blue colour were used along and near the crack front, while remaining volumes are meshed using tetrahedral elements shown in Figure 5.
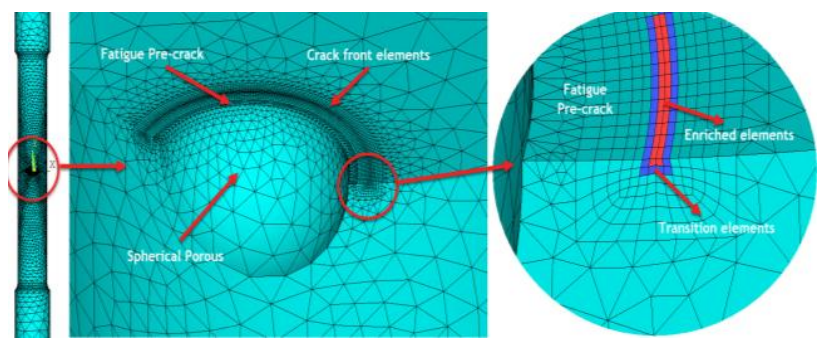

Figure 5. Detailed views of FEM model.

The finite element method (FEM) model was used to calculate some inputs for FCPAS as shown in Figure 4. FCPAS software was used to compute the SIFs along the crack tip under mixed mode loading using FRAC3D solver. The solver can compute SIFs using enriched crack front elements which do not need special mesh around the crack front [16-17]. The predicted crack propagation directions were examined by maximum tangential stress (MTS) criterion using calculated SIF. In Figure 6, variations of SIFs throughout the crack tip obtained from each growth step using FCPAS were presented. The SIF was shown a good agreement with Citarella's results.

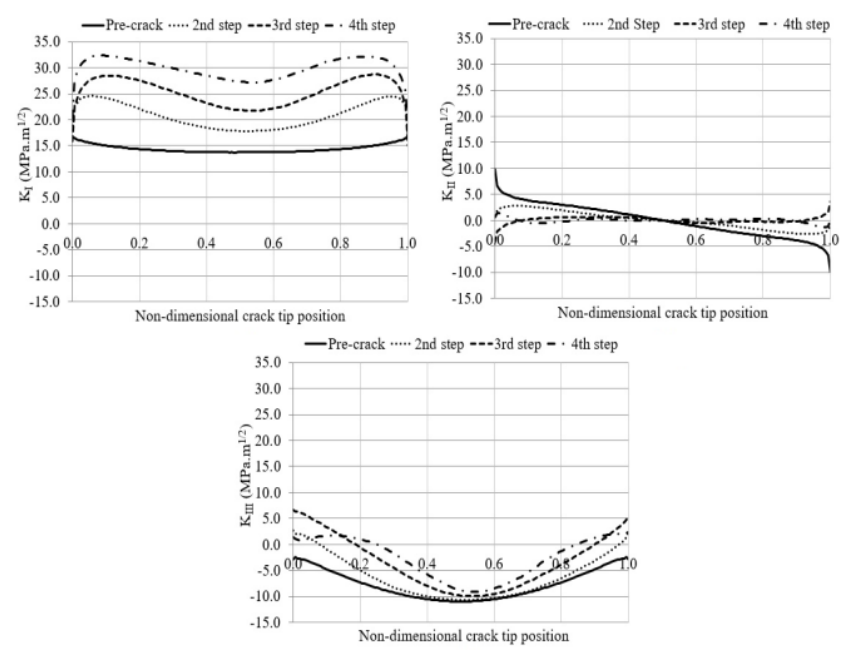

Figure 6. Distribution of $\mathrm{K}_{\mathrm{I}}, \mathrm{K}_{\mathrm{II}}$ and $\mathrm{K}_{\mathrm{III}}$ values for each step throughout the crack front.

The equivalent SIF was calculated using different criteria defined in FCPAS to compare results. When the stress intensity factor reaches the $\mathrm{K}_{\mathrm{IC}}$ value, unstable fracture occurs. Fatigue crack propagation equation of
Paris-Erdogan (Eq. (1)) was used for prediction of nodal crack propagation steps using the calculated equivalent SIF. The generated curve by FCPAS was converted to an elliptical and smooth form using SOLIDWORKS software, and then the curve was added to FEM model for crack propogation. This process was repeated until the equivalent SIF was reached to the fracture toughness $\left(\mathrm{K}_{\mathrm{IC}}\right)$ of the material. The variation of SIF values $\left(\mathrm{K}_{\mathrm{I}}, \mathrm{K}_{\mathrm{II}}\right.$ and $\left.\mathrm{K}_{\mathrm{III}}\right)$ of the 1st step (pre-crack) and 4th step were shown in Figure 7 (a-b). The Richard et. al. 3D criteria were used to calculate the equivalent SIF by FCPAS. The calculated equivalent SIF values of 4th step was 30.2, 29.9, 30.7 and 33.5 MPa. ${ }^{1 / 2}$, respectively. At the 4th step, the equivalent SIF has reached the fracture toughness of the material as shown in Figure 8, therefore the numerical analysis process for fatigue crack propagation was completed.

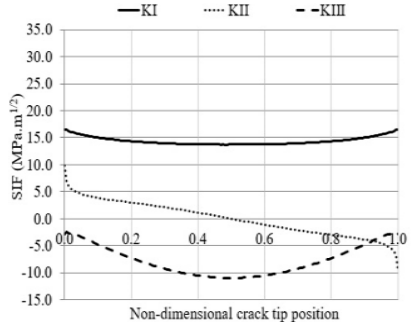

(a)

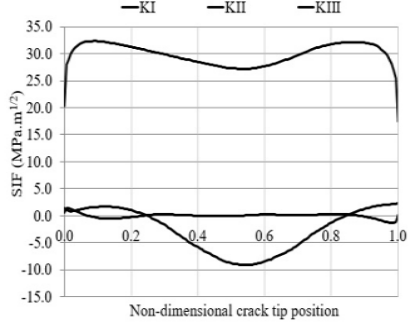

(b)
Figure 7. Variation of SIF values (a) 1st step (b) 4th step.

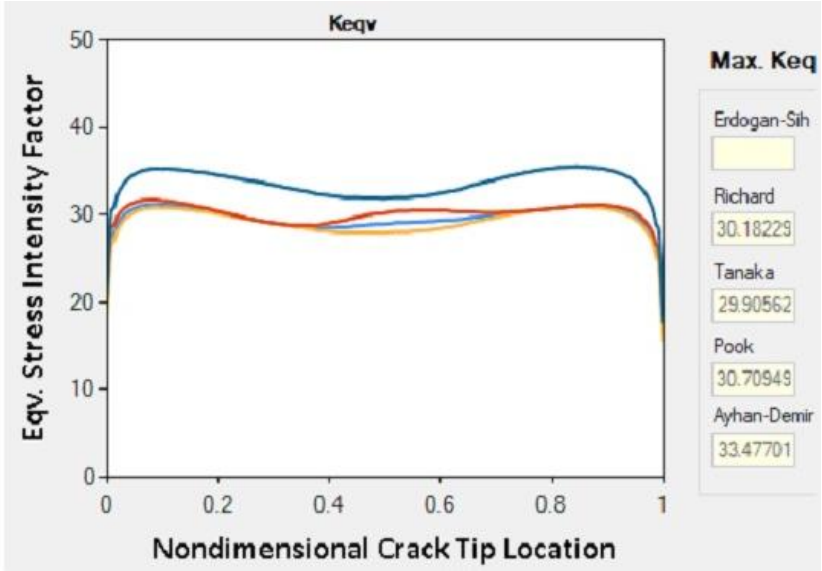

Figure 8. Variation of the calculated equivalent SIF values of 4th step by FCPAS.

\section{Results and Discussion}

Digital image examination of the specimen fracture surfaces were carried out in order to find the beginning of the stable and unstable crack growth zones as shown in Figure 9 (c). Using the examination in Figure 9 (a-b), the stable and unstable crack growth paths were also determined as shown in Figure 9(d). 

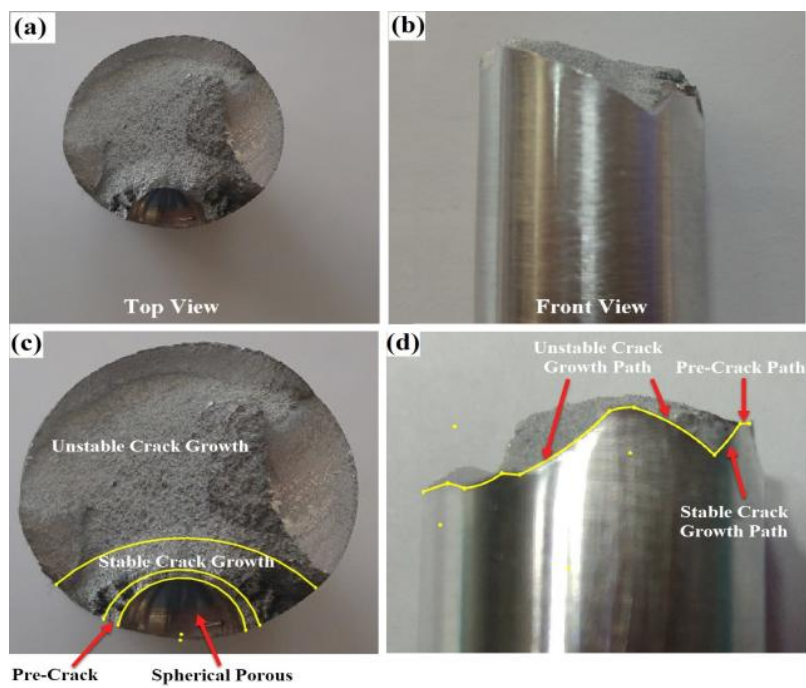

Figure 9. (a)Top, (b) Front views of the fractured specimen and (c) Zones of crack growth (d) Crack growth path.

In Figure 10, both the experimental and numerical images were overlapped to compare results. The dashed yellow line indicates the predicted the ith crack front. The simulation began with the pre-crack front determined by digital image and propagated with the calculated next crack front by FCPAS, until equivalent SIF was reached the fracture toughness. The calculated equivalent SIF for the 4th crack front was equal to the fracture toughness of the material shown in Figure 8. This means that unstable crack growth or fast fracture occurred. Very good agreements were obtained between the results of the simulation and experiment in terms of both evolving the crack growth paths and crack front as shown in Figure 10.

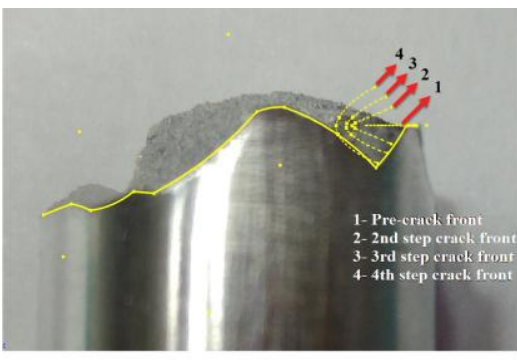

(a)

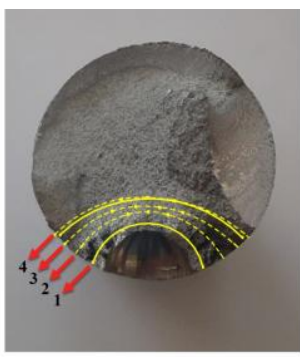

(b)
Figure 10. Overlapped views of the experimental and numerical simulation results (a) Front view, (b) Top view.

In Figure 10, the crack was propagated in-plane under Mode I loading during the pre-cracking, and then, propagation proceded out of the planes in threedimensional space in mixed mode loading, as expected.

\section{Conclusion}

In this study, numerical and experimental studies for the surface crack propagation in cylindrical bar under combined cyclic tension-torsion loads were performed. When the above results are taken into consideration, this study has primarily yielded the following conclusions.

- Finite element modeling can be used accurately for study of mixed mode (I/III) fatigue crack propagation.

- The crack propagation direction can be predicted by using the MTS criterion for mixed mode I/III fatigue crack propagation.

- Throughout the crack front, KI values in the outer points are higher than those in the interior points at initial steps of crack propagation. However, with the further propagation of the crack, the differences decrease.

- KII values are close to zero and negligible in comparison with other modes.

- KIII values in outer points are higher than those in the interior points such as $\mathrm{KI}$

- The all used criteria in FCPAS to calculate the equivalent stress intensity factor under mixed mode conditions are in very good agreement with the experimental measurements.

- There are no significant difference between the results of the simulation and experiment in terms of both evolving the crack growth paths and crack fronts.

- The presented methodology can be used to monitor the surface crack growth of the specific component at low frequency loading.

\section{Acknowledgements}

This work was supported by the Scientific and Technological Research Council of Turkey (TUBITAK), Project No: 217M690. I would like to thank Prof. Dr. Ali Osman Ayhan for allowing me to use the FCPAS software and also Strategic Products Research and Development Center (SARGEM) for the use of the facilities.

\section{References}

[1] Chandra D., Purbolaksono J., Nukman Y., 2018. Surface Crack Growth in A Solid Cylinder Under Combined Cyclic Bending-Torsion Loading. ARPN Journal of Engineering and Applied Sciences, 13(3), pp. 1033-1041.

[2] Yang Y., Chu S., Chen H., 2019. Prediction of Shape Change for Fatigue Crack in a Round Bar Using Three-Parameter Growth Circles. Applied Sciences, 9(9), p. 1751, doi:10.3390/app9091751.

[3] Lin X. B., Smith R. A., 1998. Fatigue Growth Simulation for Cracks in Notched and Unnotched Round Bars. International Journal of Mechanical Sciences, 40 (5), pp. 405-419. 
[4] Van A. L., Royer J., 1993. Part-Circular Surface Cracks in Round Bars under Tension. Bending and Twisting, 61(1), pp. 71-99.

[5] Chaves V., Beretta G., Balbín J. A., Navarro A., 2019. Fatigue Life and Crack Growth Direction in 7075-T6 Aluminium Alloy Specimens with a Circular Hole under Biaxial Loading. International Journal of Fatigue, 125, pp. 222-236.

[6] Fatemi A., Gates N., Socie D. F., Phan N., 2014. Fatigue Crack Growth Behaviour of Tubular Aluminium Specimens with a Circular Hole under Axial and Torsion Loadings. Engineering Fracture Mechanics, 123, pp. 137-147.

[7] Liu L., 2018. Modeling of Mixed-Mode Fatigue Crack Propagation, Tennessee, USA.

[8] Schollmann M., Richard H. A., Kullmer G., 2002. A New Criterion for the Prediction of Crack Development in Multiaxially Loaded Structures. International Journal of Fracture, 117, pp. 129-141.

[9] Sih G. C., Barthelemy B. M., 1980. Mixed Mode Fatigue Crack Growth Predictions. Engineering Fracture Mechanics, 13(3), pp. 439-451.

[10] Pook L., 1985. Comments on Fatigue Crack Growth under Mixed Modes I and III and Pure Mode III Loading. ASTM International, pp. 249-263, doi:10.1520/STP36227S.

[11] Demir O., Ayhan A. O., İriç S., 2019. A Novel Test System for Mixed Mode-I/II/III Fracture Tests - Part 2: Experiments and Criterion Development. Engineering Fracture Mechanics, doi:10.1016/j.engfracmech.2019.106671.

[12] Erdoğan F., Sih G. C., 1963. On the Crack Extension in Plates under Plane Loading and Transverse Shear. Journal of Basic Engineering, 85(4), pp. 519-525.

[13] Kurt E., Demir O., Ayhan A. O., 2019. Applications on Three-Dimensional Mixed Mode Fatigue Crack Propagation Using Fracture and Crack Propagation Analysis System (FCPAS). Procedia Structural Integrity, 21, pp. 32-30.

[14] Altuncu E., İriç S., 2017. Evaluation of Fracture Toughness of Thermal Sprayed and Hard Chrome Coated Aluminium-Zinc Alloy. Acta Physica Polonica A, 132(3), pp. 926-929.

[15] İriç S., Ayhan A., 2017. Dependence of Fracture Toughness on Rolling Direction in Aluminium 7075 Alloys. Acta Physica Polonica A, 132(3), pp. 892895.

[16] Ayhan A. O., Nied H. F., 2002. Stress Intensity Factors for Three-Dimensional Surface Cracks Using
Enriched Finite Elements. International Journal of Numerical Methods in Engineering, 54, pp. 899-921.

[17] Ayhan A. O., Nied H. F. 1999. Finite Element Analysis of Interface Cracking in Semiconductor Packages. IEEE Transactions on Components and Packaging Technologies, 22(4), pp. 503-511. 